\title{
Organizational Learning in Schools under Sanction
}

\author{
Kara S. Finnigan, ${ }^{1}$ Alan J. Daly, ${ }^{2}$ and Tricia J. Stewart ${ }^{3}$ \\ ${ }^{1}$ Warner Graduate School of Education, University of Rochester, Dewey Hall 1-333, Rochester, NY 14627, USA \\ ${ }^{2}$ Education Studies, University of California, San Diego, 9500 Gilman Drive, La Jolla, CA 92093-0070, USA \\ ${ }^{3}$ College of Education, Alabama State University, Abernathy Hall 344, Montgomery, AL 36101, USA
}

Correspondence should be addressed to Kara S. Finnigan, kfinnigan@warner.rochester.edu

Received 6 March 2012; Accepted 20 July 2012

Academic Editor: Alex W. H. Chan

Copyright ( $) 2012$ Kara S. Finnigan et al. This is an open access article distributed under the Creative Commons Attribution License, which permits unrestricted use, distribution, and reproduction in any medium, provided the original work is properly cited.

\begin{abstract}
The focus on "school turnaround" has become central to policy and practice in the United States as a result of school accountability, yet little remains known about school improvement under sanction. This study uses theories of organizational learning to understand the processes through which educators search for and adopt reform strategies, as well as the extent to which these schools' organizational culture and climate are conducive to this type of learning. Our mixed methods study involves document analysis, intensive case studies, and a survey of teachers in schools under sanction in a large urban school district in the USA. We found limited evidence of organizational learning, and instead evidence suggested superficial use of restructuring planning, rare diagnoses of root causes of low performance, and limited engagement in learning processes of school staff. In addition, schools relied on exploitation resulting in the recycling of previous practices. In part, the limited organizational learning in evidence was the result of structures and climates within these low-performing schools that inhibited a more learning-oriented approach to reform. Our study has implications for school improvement under accountability policies as it uncovers important challenges that limit organizational learning and, as a result, school improvement under sanction.
\end{abstract}

\section{Introduction}

The focus on "school turnaround" has become central to policy and practice in the USA since the passage of the No Child Left Behind Act of 2001 (NCLB), which designates schools as "in need of improvement" (INI). During the 2004-2005 school year, states identified more than 9,000 Title I schools as INI [1], while in 2007-2008, 30,000 schools failed to make adequate yearly progress [2]. Once schools are identified they face a series of consecutive sanctions beginning with "school improvement," followed by "corrective action," and ending with "restructuring," during which the school district must initiate plans to "fundamentally restructure the school" ([3], page 18). Recent data suggests that most schools advance to the ultimate consequences, rather than improve and move off of sanctions. In fact, the Center for Education Policy [4] found that between 2005-2006 and 2006-2007, only 10 of California's 401 Title I schools in restructuring improved enough to exit INI. Furthermore, more than 3,500 schools across the country have reached the final stage of NCLB sanctions [2].
NCLB requires that a district develop and implement a plan for each restructuring school that involves one or more of the following: (1) reopening as a charter school; (2) replacing all or most of the staff; (3) contracting with a private management company; (4) turning over the operation of the school to the state; (5) restructuring in another way, such as adopting a comprehensive reform model or hiring an external consultant [5]. While many of these options have been attempted prior to NCLB, these strategies have not been used as a widespread approach to improving low-performing schools until this point in time, nor has there been consistent research supporting these turnaround strategies. While a few studies have examined schools' responses to these accountability sanctions broadly (see, e.g., [6-8]), including examining the restructuring phase of NCLB in select states or districts $[4,9-12]$, no studies to date have examined the learning processes of schools in restructuring to understand school improvement under sanction.

The issue of underperformance is especially critical for the country's urban school districts; however, little is 
known about the process of "learning" that occurs within low-performing schools. The purpose of this study is to better understand the process through which school staff in underperforming systems diagnoe problems, search for solutions, and incorporate those strategies into efforts at reform. Specifically, we draw on organizational theories to answer the following research questions.

(1) To what degree do schools under sanctions operate as "learning organizations"?

(2) To what extent are the necessary organizational conditions present in these schools for organizational learning to occur?

In answering these questions we utilize mixed methods in exploring the processes of organizational learning in a large, underperforming, urban school district. Our data includes document analysis of restructuring plans, intensive case studies of restructuring schools, and a survey of teachers in schools in restructuring.

\section{Theoretical Framework}

Learning in education is often used to describe the process through which individual students gain knowledge or skills in school settings. However, "learning" is also important at the school and district organizational levels, particularly in the context of reform. As schools and districts, "continue to face a steady stream of novel problems and ambitious demands" ([13] pages 3-4), a deeper understanding of learning process in schools and districts that are under tremendous pressure to perform may be useful especially given the growing numbers of these systems. Our research builds upon the work of organizational learning theorists (see, e.g., [14-17]) in better understanding these processes, as described in the next section.

2.1. Defining Organizational Learning. Organizational learning is the process of detecting and correcting problems to improve organizational effectiveness [14]. Through detection and correction organizations must "question underlying assumptions that guide practice so that chosen solutions address the core problem and not merely symptoms" ([18] page 134). The process of accurately diagnosing the underlying issues facing an organization is one of the first and most crucial steps in an organization ability to "learn" and improve $[14,19]$. This suggests that the process of organizational learning involves understanding the important elements of practice, as well developing the underlying beliefs that support practice. Learning in an organizational sense leads members to change both behaviors [16] and norms [19] through a deliberate, rather than haphazard, process [20]. Recent research suggests that this learning orientation toward reform and change can have significant impact on improving organizational performance [21, 22]. However, this work is still very much in its infancy.

In order to understand the degree to which learning is taking place in schools under sanction, a better understanding of the theories of action that drive organizations is important. According to Argyris and Schön [14], theories of action represent the processes through which action is taken and outcomes are realized within an organization. These authors note that there are two types of theories of action at work: Espoused Theory, the explicit stated descriptions of the way in which the organization engages decision making; Theories in Use, those implicit processes around decisionmaking that guide action. For example, if a school has an Espoused Theory around the importance of collaboration, then one would expect that resources, representing Theories in Use, would be expended to support the espoused value of collaboration. However, there is often incompatibility between the two theories of which the individual or the collective organization may not be aware [14].

Learning involves refining theories through "single loop" learning or through "double loop" learning, which requires a more careful examination of underlying assumptions, values, and beliefs that result in the emergence of new Theories in Use. Single-loop learning is conceptualized as learning that remains within the current organizational paradigm and does not rectify the gap between Espoused Theory and Theory in Use. In other words, "how best to achieve existing goals and objectives and how to keep organizational performance within the range specified by existing norms [emphasis added]" [23]. Double-loop learning involves examining, "incompatible organizational norms by setting new priorities and weightings of norms, or by restructuring the norms themselves together with associated strategies and assumptions" [23]. This type of learning requires examination of underlying values or assumptions that at one time may have been supportive of organizational goals, but now inhibit the organization's ability to learn. A key distinction is that single loop learning refers to incremental or routine changes, while double loop learning refers to transformational or more radical change and innovation [24].

While the level of learning has been a long-standing debate in the literature, many theorists believe that organizational learning is more than just the sum of individual learning and results in institutional memory at the organizational level ([24], page 785). As Stoll [25] points out, learning processes involve dialogue, allowing members of the community to connect, discuss, and debate. In essence, organizational learning is "embedded in the deeply held beliefs and shared conceptualizations that develop among members of the organization over time as particular understandings and practices evolve through unconscious and regular interactions" ([26], page 709). Organizational learning, thus, involves social activities or the social processing of knowledge $[21,27,28]$, as individuals within the organization develop and share new knowledge and tools that result in commonly held ideas or practices or collective learning.

A final important aspect of organizational learning relates to the way in which ideas or practices enter the organization or evolve. March [17] argues that organizations require a balance between exploration (exploration of new knowledge or experimentation) and exploitation (refinement or utilization of existing knowledge). Furthermore, double-loop learning would suggest that some degree of exploration (or search for new ideas and practices outside of 
the organization) occurs as the organization moves beyond current norms and practices. Building upon the work of Levitt and March [16], Honig [29] expands upon these ideas, arguing that the search or exploration process may involve scanning the external environment for ideas or bringing individuals with expertise into the organization. In fact, this flow of information into and throughout the organization is critical to organizational learning [15]. Organizational actors "incorporate" these ideas or approaches into practice, either formally or informally and through a "retrieval" process adopt these practices over time when faced with new situations. Failing organizations are more likely to engage in limited search, selecting those strategies that result in only superficial improvement $[29,30]$.

\subsection{Factors Supporting Organizational Learning. Researchers} have identified a few key organizational conditions that support organizational learning: the culture of the organization, organizational leadership, and organizational structures. These are briefly described in the following.

Organizational cultures that support learning foster inquiry and prioritize learning for all members of the organization [31]. Research suggests that trusting relationships are a critical aspect of organizational cultures that support learning [25]. In fact, creating and supporting a climate of trust between organizational members may increase opportunities for exchanging information and innovative practices critical to improvement [32]. According to Tschannen-Moran and Hoy [33], "creating an organizational culture of cooperation rather than competition is likely to have a significant impact on the trusting and trustworthy behavior of participants" (page 573). Bryk and Schneider [34] suggest that trust is especially important for organizations that operate in turbulent environments, which is certainly the case in underperforming urban schools and districts. In addition, organizational cultures that consist of a shared belief system among organizational members have opportunities to promote learning and shared understanding [20]. Finally, a school culture that is collaborative and collegial, with norms of support, respect for individuals' ideas, and fostering a willingness to take a risk, is conducive to organizational learning [35].

Several scholars have also identified a relationship between organizational leadership and organizational learning $[20,25,28,31,35]$. Leadership that is democratic (also referred to as distributed or decentralized) has been found to be an important condition for learning to occur $[20,25,31]$. In addition, Leithwood, Leonard, \& Sharratt [35] found that transformational leadership was closely linked to organizational learning as school leaders clearly communicated the vision and expectations, while helping to strengthen the culture and providing structures to support learning throughout the school organization. In fact, Marks and Printy [36] found that the response to state accountability policies in Ohio undermined organizational learning capacity in schools by reducing participative decision making, collaborative activity, and the transfer of knowledge and skills. Similarly, two recent reviews of the organizational sciences literature $[37,38]$ note the critical aspect of school leadership in successful turnaround systems.

Finally, organizational structures can support (or hinder) organizational learning [25]. When organizational members have structured time to share ideas and practices, learning is more likely to occur $[25,31]$. Through organizational structures, individuals in the organization may have the opportunity to access ideas if these structures facilitate the dissemination of knowledge, skills, and insights [28]. Beyond these mechanisms for sharing and collaborative inquiry, Stoll [25] points out that allocated physical space for collaborative dialogue, or even proximity, that is, having a classroom near another teacher, can be conductive to organizational learning.

Thus, organizational learning comprises the "activities" of learning understood through espoused and enacted theories, single- and double-loop learning, and the process of exploration and exploitation as well as the interrelated learning "conditions" of culture, leadership, and structures. It is the interaction between the activities and conditions of learning that provides both a lens and process for organizational renewal, opportunities for learning, and better outcomes.

\section{Study Context, Methods, and Data Sources}

Our mixed methods exploratory study focuses on a large urban district serving nearly 200 schools. During the 200708 school year, 17 schools were in the final stage of PI and had been designated as "Year 5" over three school years (during 2005-2006, 2006-2007, and 2007-2008). In exploring the organizational learning within these 17 schools we collected and analyzed both qualitative and quantitative data between 2007 and 2008, including content analysis of the restructuring plans required under NCLB of all of the restructuring schools in the district, intensive case studies of two of these restructuring schools which involved interviews with school staff, and a survey of teachers in these restructuring schools.

3.1. Qualitative Data Collection and Analysis. Documents and artifacts play a unique role in codifying the identified problem and solution in low-performing schools and as such are foundational to our work. Using our theoretical lens we analyzed the improvement plans through content analysis of all 17 restructuring schools, as well as district reports and board meeting minutes related to the restructuring plan approval process, to examine the theories of action, as well as the processes, types of changes, and extent to which these altered the current structures and norms. Schools were required by the district to create workgroups comprised of parents, community members, and teachers, and in some cases, university partners were involved in the development of their reform strategies. These meetings began in the spring or summer of Year 3 (corrective action) and occurred during Year 4, with approval by the district in the spring of Year 4 . Plans were to be implemented in Year 5, or the restructuring stage of NCLB. These plans were meant to document the improvement strategies that would be implemented during 
Year 5. These workgroup meetings and the planning process that resulted were described in the school plans to varying degrees. One particularly rich example, from a middle school reported the names of the 29 members of the workgroup (half of whom were parents/community members and half of whom were school staff), along with the 13 dates that the group met. For key decisions of the workgroup, for example, a decision to implement block scheduling, the plan also notes the date the decision occurred and percent in favor (90\%).

Our qualitative data also involved case studies of two restructuring schools. Case study design is appropriate for examining complex phenomena and allows the researcher to understand a particular context or situation - in this case school failure and school improvement-from multiple perspectives using a variety of data sources, including interviews, observations, and document review [39]. Two case study sites were identified through a review of the restructuring plans of each school. These sites were selected as they represented on one hand continual underperformance as defined by remaining on PI and on the other improvement, reflected by moving off of PI. The case studies involved 10-12 interviews with administrators, teachers, and other individuals involved in the restructuring process through participation on the Program Improvement Workgroup, as well as website and document review.

For both the document review and the analysis of interview transcripts, we began by employing an inductive analysis that allowed important themes to emerge "out of the data rather than being imposed on them prior to data collection and analysis" ([40], page 390). We also drew on constant comparative analysis method [41, 42] through checking and rechecking emerging themes [43]. This process of constant comparison "stimulates thought that leads to both descriptive and explanatory categories" ([44], page 341 ) and provides a deeper more nuanced understanding of the data from the reports. Our data was further analyzed through the lens of organizational learning as defined in our literature review. For example, we analyzed these data to better understand the underlying theories of action in these schools, extent to which single- or double-loop learning was occurring, and indication of the social processing of knowledge. Furthermore, we coded these data to uncover aspects of these organizations that have been found to facilitate or hinder learning involving the culture, leadership, and structures of these organizations.

3.2. Quantitative Data Collection and Analysis. Although our study was primarily grounded in our qualitative data, we also gathered descriptive data from a survey of restructuring school teachers. In total, 614 teachers from 13 of the 17 restructuring schools responded to the survey. (All schools were contacted but two were facing extreme internal conflicts and did not feel that they could commit the time, and two did not respond to our requests.) The instrument, which was piloted with practitioners, focused on restructuring planning, specific interventions, organizational learning, social processes related to improvement efforts, and perceptions of restructuring plan implementation and impact. In addition, we asked a number of demographic and open-ended questions related to problem identification and strategy implementation. The anonymous survey took approximately 25 minutes to complete and was administered during a staff meeting at each school in spring 2008.

Survey participants included educators in various positions at these schools. Seventy-one percent of the respondents were classroom teachers, twelve percent were other certificated staff, nine percent were support teachers, the rest were classified staff (four percent) and school administrators (four percent). Respondents had worked in their current positions for an average of 7.5 years (range: 1-35). In addition, respondents had worked at their current schools for an average of 6 years (range: $1-40+$ ). Finally, eighty-seven percent of respondents reported that the school was their first choice for the 2007-08 school year. Our exploratory analysis of these survey data include descriptive statistics, including response frequencies, as well as significance testing to determine differences in subpopulations, such as differences based upon length of time at the school.

3.3. Limitations. There were several limitations related to the collection of data. For example, the timing of data collection required individuals to recall events that had past and were also part of an ongoing process. This resulted in some interview participants at times struggling to articulate what they wanted to share as they were forced to jog their own memories. A similar limitation is that given the nature of turnover in the individual schools, not all survey participants had the same depth of understanding of the topic and school history. While these are realities of the data collection time frame and process, they do not limit the quality of the information that was provided and that we were able to triangulate through the various data sources.

\section{Results}

In this section, we weave together the qualitative and quantitative data to support several large themes from our analysis:

(i) superficial use of restructuring plans;

(ii) rare diagnosis of root causes;

(iii) limited social processing and collaborative inquiry;

(iv) recycling of "old" ideas and practices;

(v) structures and climates that inhibited learning.

These themes are described in more detail in the Sections that follow.

4.1. Superficial Use of Restructuring Plans. As mentioned above, the district required that all restructuring schools develop a formal Program Improvement (PI) Workgroup to create a restructuring plan. Our data indicate that these workgroups were primarily used by school leaders in superficial ways rather than as a process through which organizational learning could take place. This was particularly apparent in the survey data, which showed a low level of knowledge about, and involvement in, the development of the plans, as well as limited understanding about the 
restructuring process at their schools. An indicator of the more superficial use of these plans was the low level of staff familiarity with the plan. While 36 percent were very familiar, 49 were only somewhat familiar and 15 percent were not familiar at all with their schools' restructuring plans. Perhaps not surprisingly, the administrators were more likely to be familiar with the plans than other staff at the schools. In addition, we found a statistically significant difference $(P<0.05)$ based upon length of time at the school (using chi-square testing) - respondents who had been at the school for more than two years were more likely to be familiar with these plans than those newer to the school. Beyond familiarity we found low levels of involvement, with 39 percent informally involved in the development of the plans and only 21 percent formally involved. In addition, 12 percent of the teachers purposefully chose not to be involved in plan development. However, almost a third (29\%) of the staff indicated noninvolvement because they were not part of the staff at that time. A common problem in low-performing schools is a high degree of turnover, which may certainly impact the ability of the organization to learn at deep and sustained levels. Given that schools had developed these plans within the previous three years our data uncovers that a large proportion of staff joined these schools after restructuring. This lack of understanding of and involvement in the plans suggest that the plans were not living, dynamic documents that guided coherent efforts at improvement, rather they were more perfunctory artifacts of technical accountability demands that were flexed to meet the existing needs of the schools as one of the case study schools demonstrates.

This Program Improvement Workgroup plan and the required meetings were used for information sharing with parents and community members and to gain buy-in rather than as an authentic tool to develop shared strategies around improvement. The principal of this school noted the following.

First of all I realized from the get-go how much we needed to lay the foundation of exactly what was happening. I mean, when I had a parent slam her fist into the desk and say how much she hated [Superintendent] and when I said "why?" she said "well, he's the one that created No Child Left Behind," then I knew I had my work cut out for me.

Establishing buy-in was particularly necessary given the high levels of frustration a core group of involved parents and community members had with the district. As the principal described, "they were sick and tired of being ignored and having their kids in a failing school. They actually felt and articulated so well, this disenfranchisement that they felt with the district and they took it so personal and I think, maybe, rightly so." The principal also expressed working to get the staff "on board" which she noted was challenging because of union "scare tactics" designed to stop them from becoming a charter school, which was one of the options available under NCLB for restructuring). Another respondent shared that "honestly, I do feel that it was really a state dictated document. .. many of the issues don't go with API or APY or CYSP, which are our goals for running the school." This type of disconnect can help explain the lack of buy- in articulated in the survey by senior staff members.

We also found that survey respondents did not appear to have a strong grasp of the restructuring planning process. Forty percent did not know if the development of the restructuring plan was different from their normal planning process at the school. On the other hand, 16 percent reported that it was very different, 34 percent reported it was somewhat different, and nine percent reported there was no difference from their normal planning process. At one of our case study schools, the staff described the restructuring process as similar to what they had previously done in terms of improvement planning, but more formal and even more threatening than usual because they had to give their plan to the school board. Several people at the school reported that this was not an authentic attempt to reflect on their problems and develop a plan. For example, one person indicated that their staff did not examine what caused students to drop out to better understand how they could reduce the dropout rates. Another teacher noted that at the beginning she felt it was authentic, but as the process went on she became more disenfranchised because she felt that there was a focus on what the board would accept rather than what they thought they needed to do to improve. Several people complained about being rushed to meet board deadlines, while others complained that the plan was too heavily shaped by their university partners and school administrators. Overall, staff were only superficially involved in the restructuring planning process and had limited knowledge of its components.

4.2. Rare Diagnoses of Root Causes. Our findings suggest that rather than examining data to identify root causes of problems, the workgroups focused on the score deficiencies-in other words, the low scores were considered the problem that "caused" continual underperformance. With a few exceptions, the discussions regarding the restructuring school's "problems" or "challenges" were linked to English Language Arts (ELA) or Math scores for different subgroups of students or turnover of staff. As one staff member noted, they focused too much on the numbers, for example, dropout rates, and not enough on the interpretation, or what he called the "why's and what if's." Although this previous point was not widely shared in our interviews, it does suggest that some staff were aware of the lack of depth associated with careful problem diagnosis. This lack of deeper engagement may have been the unintended result of a template or assistance provided by the district or an external consultant because many of the proposals followed the same format and had nearly identical wording (see Table 1). Many of the plans, which in theory were meant to target specific school needs around improvement, reflected the general template provided by the district and as such may have played a more perfunctory role.

Alternatively, some of the plans focused on performance targets, such as certain percentages of students passing the ELA assessment, and identified ways in which the targets 
TABLE 1: Listing of primary challenges in two schools' restructuring plans.

Elementary school 1 (cohort 3)

How to improve schoolwide academic performance and the performance of all subgroups of students, in particular,

(i) How to improve the performance of students with disabilities in English language arts and mathematics.

(ii) How to improve the performance of Hispanic students in English language arts.

(iii) How to improve the performance of African American students in language arts and in mathematics.

(iv) How to improve the performance of English learners in English language arts.

How to improve the performance of socioeconomically disadvantaged students in English language arts.

(i) How to improve mathematics education for all students.

(ii) How to improve the rate at which English language

learners gain English fluency.

(iii) How to improve parent involvement in the education of their children.
Middle school 1 (cohort 3)

How to improve schoolwide academic performance and the performance of all subgroups of students, in particular,

(i) How to improve the performance of Hispanic students in English language arts and in mathematics.

(ii) How to improve the performance of English learners in English language arts and in mathematics.

(iii) How to improve the performance of students with disabilities in English language arts and in mathematics.
How to improve the performance of socioeconomically disadvantaged students in mathematics.

(i) How to increase the rate at which English learners gain English fluency.

(ii) How to improve parent involvement in the education of their children, particularly the involvement of parents of students from VEEP feeder schools and of English learners. would be reached (e.g., through programmatic or structural changes). However, even in those more "data-driven" plans, there is a lack of evidence suggesting the root cause of the problem was considered (e.g., why were the math scores low for a particular sub-group of students or why was teacher turnover high at the school)? Instead, much of the restructuring plans focused on initiatives that would be adopted or were clearly already in place. Only one middle school restructuring plan of the 17 in the district specifically addressed the question of "why are we failing?" by clearly identifying problem areas that may lead to low-performance outcomes and linking these to the restructuring initiatives.

\subsection{Limited Social Processing and Collaborative Inquiry.}

Much of the literature on organizational learning involves the social processing of meaning making and knowledge exchange as individuals within the organization develop new ideas and tools and share these in a way that results in commonly held beliefs or practices. The importance of this process cannot be overstated, as it is through the exchange of knowledge and coconstruction of reform strategies that shared beliefs and behavior can result. We found that overall the social processes involving sensemaking and the development of shared action were not common practices in the restructuring schools. Data from the survey found that respondents were most likely to work in teacher teams to respond to student needs with 41 percent doing this weekly, yet a full 12 percent never practiced this. Additionally, 20 percent or less reported any of the other activities, such as discussing assessment results, analyzing student work, observing other teachers' classrooms, or attending meetings on a weekly basis. Equally troubling is that restructuring staff also rarely observed other teachers' classrooms or coached or mentored other teachers, with 41 and 47 percent, respectively, reporting that they never did these things. That so few participants participate in these activities weekly suggests that meaningful sustained learning encounters would be difficult to achieve.

One of our case study schools suggests a challenge around the social processing of knowledge given the high level of staff turnover. This school retained 40 percent of the staff in the first year of restructuring and a few years later had just seven of original staff members (prerestructuring) remained. Teachers described the process of "rolling out" the work of the "old-timers" to new staff as the changes that they made to the school had led to different expectations, roles, and responsibilities. Teacher turnover was also a big issue in our other case study school, with one teacher noting that not only did the staff change, but both the school administrators and university leadership had also changed in the years since they had moved onto PI restructuring. One respondent not only expressed frustration that goes with turnover but also how this relates to the plans that have been put into place: "the principal started off this year as interim until finally we convinced the wise old guys [district office] that they should leave him as principal...so we may be adjusting as we go...with changes to the plan." Creating collective or shared norms and expectations with a large proportion of teachers new to the sites was a major challenge and appeared to inhibit progress.

4.4. Recycling of "Old" Ideas and Practices. As discussed previously, the literature on learning organizations suggests the importance of a balance between exploration, which involves access to new knowledge or experimentation, and exploitation, or the refinement or utilization of existing 
knowledge. One way to acquire new knowledge or ideas is through connections with others outside of your organization. For example, the decision to "go charter" at one of our case study schools was highly influenced by the superintendent. The Director pointed out that teacher turnover had been very high at the school, "there had been a litany, a revolving door of leaders and teachers in here, so to restaff the school would just be like, we've been there, done that." The school received assistance from the district's school choice office, guiding them through the steps of getting parents involved, writing the charter petition, acquiring signatures, and transporting community members to the board meeting. The Superintendent recommended that a team from the school visit, another school across the country that had a similar population and had been successful after becoming a charter school, and the staff reported that many of their ideas for moving forward came from that visit. Although systematic exploration was evident in this one school, efforts around this were the exception not the rule.

Most of the information or approaches that these schools utilized appeared to emerge from within the school (through teachers or administrators), or exploitation, with little exploration occurring, or new information coming into these organizations from the outside (through teachers at other schools or central office staff). Teachers were most likely to go to other teachers within their school (versus teachers outside of the school, central office staff, or some "other" individual or group) regarding instructional strategies (89\%) and curricular issues (87\%). One of the problems associated with this was described by a participant who shared "we're running into some old practices that may not be as effective but people are slowly opening up." In fact, the survey data showed that only eight percent of teachers went to teachers outside of their school for these ideas or issues. Teachers were even less likely to go to someone outside of their school when faced with a problem with students, gain support tackling a difficult situation, or when concerned about leadership with each of these occurring less than $5 \%$ of the time. This reflects more of an emphasis on single-loop learning, or the "recycling" of old ideas and approaches, suggesting that this type of learning was driving improvement efforts.

4.5. Structures and Climates That Inhibited Learning. Schools that have the capacity for organizational learning include supportive conditions such as a strong professional community, access to new ideas, strong leaders, and internal standards of accountability [28]. However, we found that the restructuring schools had somewhat weak school climates when considering the extent to which they were collegial or worked in collaborative cultures-the type that is most conducive to organizational learning [35]. In fact, 40 percent of respondents were unsatisfied or very unsatisfied with the level of communication in their school and 34 percent were unsatisfied or very unsatisfied with the level of collaboration. However, slightly more than half of the respondents reported somewhat high levels of trust among teachers (54 percent), and nearly half reported somewhat high levels between teachers and administrators (43 percent), yet this left a substantial proportion that felt trust was low among teachers
(16 percent) and between teachers and administrators (26 percent). We found significant differences in trust relationships between groups of teachers. For example, teachers who were newer to the school reported higher levels of trust between teachers and administrators than those who had been at the school for longer periods (more than six years). An example from one of the case study participants sums this idea up nicely., "And it bothered me, because I was like 'well, don't you think this is better for the community?...I was so new and still looking for so much more. Like, optimism, I guess, still looking for the greater good." This individual not only reflects more trust in the process of restructuring but also articulates a desire that with hindsight she found lacking in others who were more senior and had been at the school longer.

While a high proportion of the respondents reported a belief in the staff being committed to school improvement at their schools, with 69 percent reporting that all or most of the certificated staff and 62 percent reporting that all or most of the classified staff were committed it is questionable given the lack of communication in place that this commitment results in organizational learning. In addition, our data suggests positive leadership conditions at these schools, especially regarding the leadership team being committed to improvement (90\%) and supportive of teachers $(81 \%)$. Our charter case study school provides an example of improved leadership conducive to organizational learning. After restructuring, leadership was distributed to other members of the school community through the development of an informal leadership team. This teacherled team included representatives from each department and grade level and was primarily responsible for developing new policies and curriculum that resulted from restructuring. One respondent shared the breadth of the type of work that this teacher led team covered: "we brought everybody on board with the exact structures we wanted-quick questions, walking in lines, the uniform expectations, the discipline procedures, and so forth and at the same time [over the summer] we started working on curriculum.. like what our units of study would be throughout the year." This quote shows the type of change that can be accomplished but it does require a dedicated and constant workforce. However, as already noted, teacher turnover was a major challenge at our case study schools, which was further supported by the survey data that indicates 35 percent of teachers believed that teacher turnover was a major challenge for the school.

Given the limited organizational learning in evidence in these schools, and lack of conducive environments that foster this type of learning, it is not surprising that most respondents believed that their school's restructuring efforts have had only small, but positive results. Table 2 shows some of the positive changes that teachers' perceived had resulted from restructuring from changes in curriculum and instruction to changes in academic outcomes. Similarly, while 18 percent believed that little or no change had occurred as a result of being under accountability policy sanctions, another 41 percent reported small but important changes and 35 percent reported considerable improvements. The type of radical changes necessary for double-loop learning to occur, 
TABLE 2: Changes at the school that occurred as a result of restructuring.

\begin{tabular}{lccc}
\hline & \multicolumn{2}{c}{$\begin{array}{c}\text { Percentage of Respondents }\left(n=485^{*}\right) \\
\text { Negative change has resulted }\end{array}$} & No change has resulted \\
\hline Changes in curriculum and instruction & $67 \%$ & $11 \%$ & $22 \%$ \\
Changes in school structures & $64 \%$ & $13 \%$ & $23 \%$ \\
Changes in non-academic outcomes & $61 \%$ & $8 \%$ & $31 \%$ \\
Changes in staff relationships & $52 \%$ & $18 \%$ & $30 \%$ \\
Changes in academic outcomes & $49 \%$ & $15 \%$ & $35 \%$ \\
\hline
\end{tabular}

* Note: a large proportion of teachers who were new to the school skipped this question.

however, was not taking place, as only six percent of teachers reported that fundamental reforms had resulted.

\section{Summary and Implications}

Our mixed method study explored the degree to which schools in restructuring were learning organizations. Results suggest that problem identification, identified strategies, and evaluation of progress were primarily engaged at a level of single-loop learning. Our data further indicates that educators rarely sought new ideas or expertise outside of their immediate environment. The extreme pressures and short timelines these schools faced in making significant improvement may have limited the exploration capabilities of the schools. This resulted in the "repackaging" or "recycling" of ideas and approaches that did not support the meeting of organizational goals or contribute to learning within the organization. While the schools espoused a commitment to meeting the needs of students through an in-depth collaborative planning process, the schools' Theories in Use suggest that the plans were relatively superficial responses to these accountability sanctions.

Our findings suggest that low performing schools do not necessarily engage in double-loop learning. We saw little evidence of, for example, ensuring that all members of the organization learn the norms and expectations; facilitating the sharing of knowledge, skills, and insights; or fostering inquiry about the root causes of low-performance. While the Workgroup had the potential to facilitate an authentic process for identifying core problems, schools tended to incorporate their processes from previous school improvement efforts and piggyback upon the changes that they had already put into place. As a result, instead of truly reflecting on their schools' contexts, diagnosing the problems facing their schools, and determining appropriate approaches or strategies to bring about school change, they developed a plan that focused on symptoms not causes and outlined various piecemeal changes that were unlikely to have a large impact. The learning that was taking place within these schools is most akin to single-loop learning in which decisions and actions were primarily occurring within the existing structure and norms of the organization. One exception was our case study school that had, according to school staff, fundamentally changed norms, roles, and expectations through becoming a charter school.

School staff did not tend to have shared learning experiences in which they could strengthen existing knowledge and skills and develop new knowledge and skills by engaging in joint work. For example, they rarely analyzed student work together, observed other teachers' classrooms, coached or mentored other teachers, or attended professional development addressing their school's challenges. The interactions that were reported could be categorized as low depth engagement with the reforms as described by Coburn \& Russell [45], with more focus on the technical structures and procedures.

The restructuring schools had some evidence of being organizations that were on the right track toward having the organizational factors that were conducive to learning. In fact, respondents reported fairly high levels of trust, commitment, and leadership. However, there were large factions that reported low levels or dissatisfaction in each area. Perhaps not surprising, the most dissatisfied were those who did not choose the school or had been at the school for longer periods of time. In fact, our data suggest that the restructuring schools had somewhat high levels of trust to build upon as they engaged in the difficult work ahead.

Our study suggests that restructuring schools will have difficulty turning around from persistent failure given the limited learning taking place in these schools. Given the scholarship around organizational learning and lessons learned from these underperforming schools the following paragraphs represent some important elements for consideration of effective "school turnaround" approaches.

Careful Diagnosis of Root Cuses of Low Performance and Clear Strategies That Address These. In these schools a strict focus on the scores as the "problem" rather than an examination of the deeper issues causing these low scores permeated. This approach lacked the important "questioning of underlying assumptions that guide practice so that chosen solutions address the core problem and not merely symptoms" ([18], page 134). Carefully examining root causes of low performance will require the schools to engage in a process of examining Espoused Theories versus Theories in Use to better reconcile the gaps between these. Our study suggests that district timelines made the diagnoses and building of plans difficult given that schools had approximately six months to undertake this difficult task. While schools had as many as 22 meetings of their workgroups, authentic learning did not appear to occur. In part this was linked to the templates that the schools used which did not facilitate consideration of the underlying causes of educational failure. 
Perhaps driven by the NCLB legislation itself, schools started from the end point, that is, which restructuring option they would select. Furthermore, our study suggests that the high levels of conflict and turnover in these schools make learning more difficult. These plans could help prompt the learning process by engaging school staff in joint problem solving and, in essence, allowing them to develop a common shared perspective of both the underlying problems in their school and potential solutions or reform strategies. To direct schools toward the double-loop learning process, districts could require that schools identify the root causes for each area that they did not meet Annual Yearly Progress as well as a rationale for each restructuring strategy that demonstrates how it aligns with the underlying problem.

Reduction of Isolation of These Schools to Allow New Ideas to Emerge. Given the internal focus of the schools, district staff should find ways to link restructuring schools to other resources within and outside of the district to reduce the isolation of these schools and allow more exploration, so that new ideas and practices could inform their reform efforts rather than continuing to recycle "old" ideas and practices. Educators at one of our case study schools noted that the link to the university partner provided them with access to a wealth of ideas, as well as legitimacy in the community. However, they did not report connections to other nearby schools or even those that serve similar populations. Given that many of these schools serve similar students it may be useful to intentionally build connections between small groups of the low-performing schools in the district, as well as link them more formally to higher-performing schools in the district, an effort to leverage existing knowledge between schools. Providing a structured opportunity to share and disseminate practices may build the organizational learning capacity of restructuring schools.

Districts and States Must Balance Support with the Demands of NCLB Sanctions. Districts must negotiate the tension between support and bureaucratic demands in order to move restructuring schools to the next level of performance. As McLaughlin [46] notes it is this combination of pressure and support that will lead to successful policy implementation. NCLB requires that districts and states provide technical assistance to schools in restructuring [3]. While the legislation notes that states must establish school support teams, use teachers and principals from successful schools, and devise other approaches for providing assistance through for example, universities or private providers, it does not specify the ways in which districts might support the restructuring schools in particular. Districts and states would benefit from clear and strategic approaches to supporting these schools by allocating resources to build internal capacity around restructuring planning, as well as provide opportunities for developing stronger networks across schools to support not only the technical aspects of improvement planning, but also organizational learning processes as these schools undergo complex change.

Overall, our findings suggest that more work is necessary to ensure that accountability policies enable schools to undertake the organizational learning process of diagnosing problems, developing new knowledge, and identifying solutions to bring about school improvement. This is of utmost importance in the USA and other educational contexts. The technical emphasis of the policies, themselves, and implementation within districts and schools do not encourage more complex organizational learning processes that are necessary in improving outcomes. In essence, while these policies demand improvement, the design and implementation in many ways seem to be in direct opposition to supporting organizational learning, ultimately limiting school turnaround. Our study suggests that underperforming schools and districts will be unable to meet the expectations of accountability policies without more focused attention on the learning processes as staff undertake complex reform without a clear understanding of the underlying causes of low performance or sufficient knowledge and skills to tackle these challenges. The need to address these pervasive issues becomes an issue of social justice, as these chronically underperforming schools and districts typically serve populations that have been marginalized for much too long.

\section{References}

[1] S. Stullich, E. Eisner, J. McCrary, and C. Roney, National Assessment of Title I: Interim Report, Volume I: Implementation of Title I, Institute of Education Sciences, National Center for Education Evaluation and Regional Assistance, U.S. Department of Education, Washington, DC, USA, 2006.

[2] D. J. Hoff, "Schools struggling to meet key goal on accountability," Education Week, vol. 28, no. 16, 3 pages, 2009.

[3] U.S. Department of Education, Child Left Behind: A Desktop Reference, Washington, DC, USA, 2002.

[4] Center on Education Policy, Beyond the Mountains: An Early Look at Restructuring Results in California, Washington, DC, USA, 2007.

[5] U.S. Department of Education, "LEA and school improvement: non regulatory-guidance (Revised)," Washington, DC, USA, 2006, http://www.ed.gov/policy/elsec/guid/schoolimprovementguid.doc.

[6] C. Bitter, M. Perez, T. Parrish et al., Evaluation Study of the Immediate Intervention/Underperforming Schools Program of the Public Schools Accountability Act of 1999, American Institutes for Research, Palo Alto, Calif, USA, 2005.

[7] H. Mintrop and T. Trujillo, "Corrective action in low performing schools: lessons for NCLB implementation from firstgeneration accountability systems," Education Policy Analysis Archives, vol. 13, no. 48, pp. 1-27, 2005.

[8] J. O'Day and C. Bitter, Evaluation study of the Immediate Intervention/ Underperforming Schools Program and the High Achieving/Improving Schools Program of the Public Schools Accountability Act of 1999, American Institutes for Research, Palo Alto, Calif, USA, 2003.

[9] Center on Education Policy, Wrestling the Devil in the Details: An Early Look at Restructuring in California, Washington, DC, USA, 2006.

[10] Center on Education Policy, What Now? Lessons from Michigan about Restructuring Schools and Next Steps Under NCLB, Washington, DC, USA, 2007. 
[11] L. M. Rhim, Restructuring Schools in Baltimore: An Analysis of State and District Efforts, Education Commission of the States, Denver, Colo, USA, 2004.

[12] L.M. Rhim, Restructuring Schools in Chester Upland, Pennsylvania: An Analysis of State Restructuring Efforts, Education Commission of the States, Denver, Colo, USA, 2005.

[13] K. Leithwood, D. Jantzi, and R. Steinbach, "An organisational learning perspective on school responses to central policy initiatives," School Leadership and Management, vol. 15, no. 3, pp. 229-252, 1995.

[14] C. Argyris and D. A. Schön, Organizational Learning II: Theory, Method, and Practice, Addison-Wesley Publishing Company, Reading, Mass, USA, 1996.

[15] G. P. Huber, "Organizational learning: the contributing processes and the literatures," Organization Science, vol. 2, no. 1, pp. 88-115, 1991.

[16] B. Levitt and J. G. March, "Organizational learning," American Review of Sociology, vol. 14, pp. 319-340, 1988.

[17] J. March, "Exploration and exploitation in organizational learning," Organization Science, vol. 2, no. 1, pp. 71-87, 1991.

[18] J. P. Scribner, K. S. Cockrell, D. H. Cockrell, and J. W. Valentine, "Creating professional communities in schools through organizational learning: an evaluation of a school improvement process," Educational Administration Quarterly, vol. 35, no. 1, pp. 130-160, 1999.

[19] V. Collinson and T. F. Cook, Organizational Learning: Improving Learning, Teaching, and Leading in School Systems, Sage, Thousand Oaks, Calif, USA, 2007.

[20] C. M. Fiol and M. A. Lyles, "Organizational learning," The Academy of Management Review, vol. 10, no. 4, pp. 803-813, 1985.

[21] L. Hubbard, H. Mehan, and M. K. Stein, Reform as Learning: School Reform, Organizational Culture, and Community Politics in San Diego, Routledge, New York, NY, USA, 2006.

[22] M. S. Knapp, "How can organizational and sociocultural learning theories shed light on district instructional reform?" American Journal of Education, vol. 114, no. 4, pp. 521-539, 2008.

[23] C. Argyris and D. Schön, Organizational Learning: A Theory of Action Perspective, Addison Wesley, Reading, Mass, USA, 1978.

[24] M. Easterby-Smith, M. Crossan, and D. Nicolini, "Organizational learning: debates past, present and future," Journal of Management Studies, vol. 37, no. 6, pp. 783-796, 2000.

[25] L. Stoll, "Connecting learning communities: capacity building for systemic change," in Second International Handbook of Educational Change, A. Hargreaves, A. Lieberman, M. Fullan, and D. Hopkins, Eds., pp. 469-484, Springer International, Dordrecht, The Netherlands, 2009.

[26] J. Supovitz, "Knowledge-based organizational learning for instructional improvement," in Second International Handbook of Educational Change, A. Hargreaves, A. Lieberman, M. Fullan, and D. Hopkins, Eds., pp. 707-723, Springer International, Dordrecht, The Netherlands, 2009.

[27] J. Bransford, S. Mosberg, M. A. Copland et al., "Adaptive people and adaptive systems: issues of learning and design," in Second International Handbook of Educational Change, A. Hargreaves, A. Lieberman, M. Fullan, and D. Hopkins, Eds., pp. 825-856, Springer International, Dordrecht, Netherlands, 2009.

[28] H. M. Marks and K. S. Louis, "Teacher empowerment and the capacity for organizational learning," Educational Administration Quarterly, vol. 35, pp. 707-750, 1999.

[29] M. I. Honig, "District central offices as learning organizations: how sociocultural and organizational learning theories elaborate district central office administrators' participation in teaching and learning improvement efforts," American Journal of Education, vol. 114, no. 4, pp. 627-664, 2008.

[30] J. A. O’Day, "Complexity, accountability, and school improvement," Harvard Educational Review, vol. 72, no. 3, pp. 293329, 2002.

[31] V. Collinson, T. F. Cook, and S. Conley, "Organizational learning in schools and school systems: improving learning, teaching, and leading," Theory into Practice, vol. 45, no. 2, pp. 107-116, 2006.

[32] A. C. Costa, R. A. Roe, and T. C. B. Taillieu, "Trust implications for performance and effectiveness," European Journal of Work \& Organizational Psychology, vol. 10, no. 3, pp. 225-244, 2001.

[33] M. Tschannen-Moran and W. K. Hoy, "A multidisciplinary analysis of the nature, meaning, and measurement of trust," Review of Educational Research, vol. 70, no. 4, pp. 547-593, 2000.

[34] A. S. Bryk and B. Schneider, Trust in Schools: A Core Resource for Improvement, Russell Sage Foundation, New York, NY, USA, 2002.

[35] K. Leithwood, L. Leonard, and L. Sharratt, "Conditions fostering organizational learning in schools," Educational Administration Quarterly, vol. 34, no. 2, pp. 243-276, 1998.

[36] K. M. Marks and S. M. Printy, "Organizational learning in high-stakes accountability environments: lessons from an urban school district," in Theory and Research in Educational Administration, W. K. Hoy and C. G. Miskel, Eds., pp. 1-39, Information Age, Charlotte, NC, USA, 2002.

[37] J. Murphy, "Turning around failing organizations: insights for educational leaders," Journal of Educational Change, vol. 11, no. 2, pp. 157-176, 2010.

[38] J. Murphy and C. V. Meyers, Turning around Failing Schools: Lessons from the Organizational Sciences, Corwin Press, Thousand Oaks, Calif, USA, 2008.

[39] R. K. Yin, Case Study Research, Design and Methods, Sage, Newbury Park, Calif, USA, 3rd edition, 2003.

[40] M. Q. Patton, Qualitative Evaluation and Research Methods, Sage, Newbury Park, Calif, USA, 2nd edition, 1990.

[41] H. Boeije, "A purposeful approach to the constant comparative method in the analysis of qualitative interviews," Quality and Quantity, vol. 36, no. 4, pp. 391-409, 2002.

[42] B. G. Glaser and A. Strauss, The Discovery of Grounded Theory: Strategies for Qualitative Research, Aldine, Chicago, Ill, USA, 1967.

[43] M. B. Miles and A. M. Huberman, Qualitative Data Analysis, Sage, Thousand Oaks, Calif, USA, 2nd edition, 1994.

[44] Y. S. Lincoln and E. G. Guba, Naturalistic Inquiry, Sage, Beverly Hills, Calif, USA, 1985.

[45] C. E. Coburn and J. L. Russell, "District policy and teachers' social networks," Educational Evaluation and Policy Analysis, vol. 30, no. 3, pp. 203-235, 2008.

[46] M. W. McLaughlin, "Learning from experience: lessons from policy implementation," Educational Evaluation and Policy Analysis, vol. 9, no. 2, pp. 171-178, 1987. 


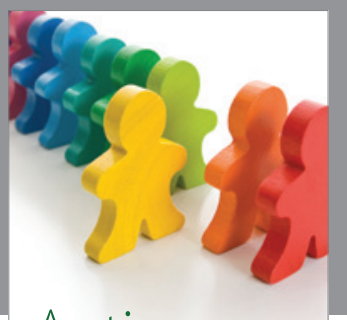

Autism

Research and Treatment
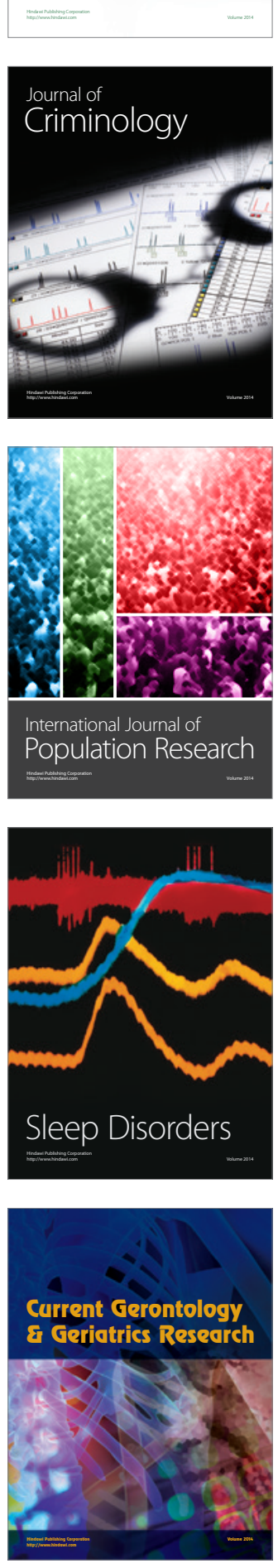
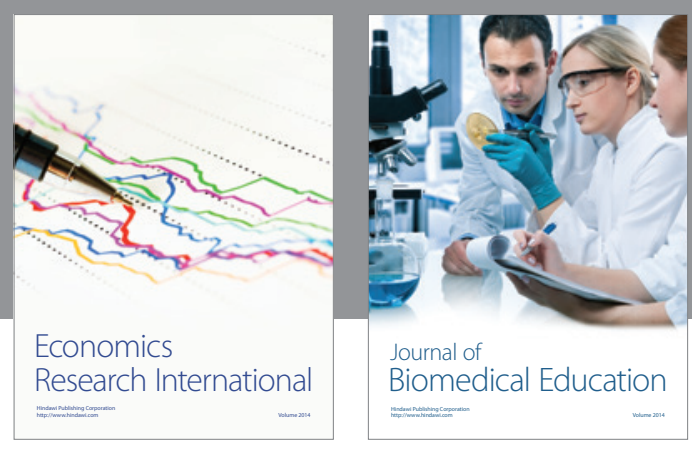

Journal of

Biomedical Education

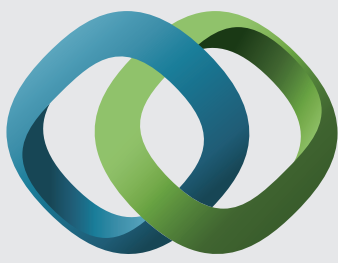

\section{Hindawi}

Submit your manuscripts at

http://www.hindawi.com
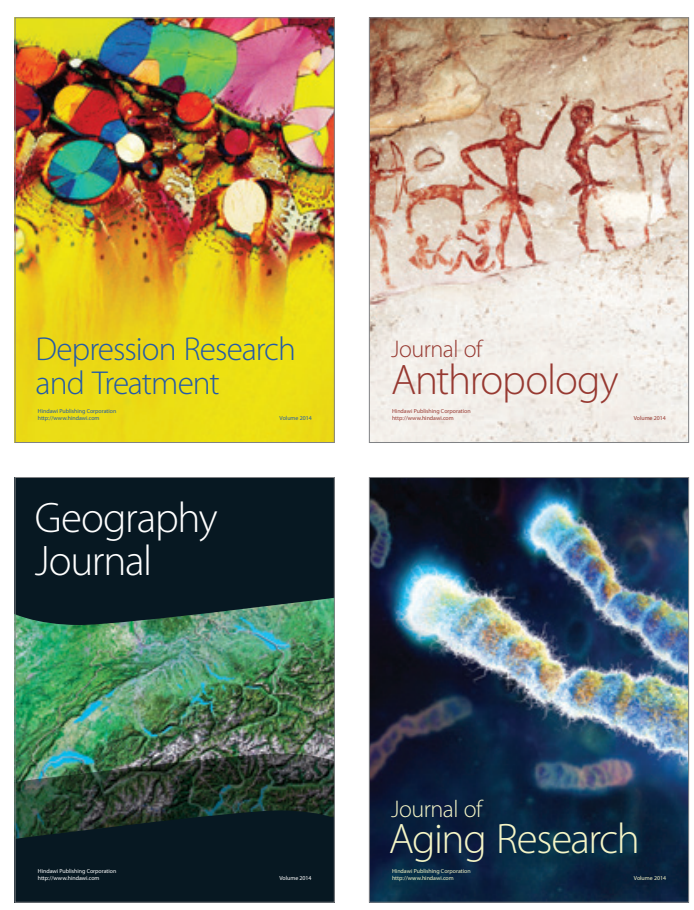

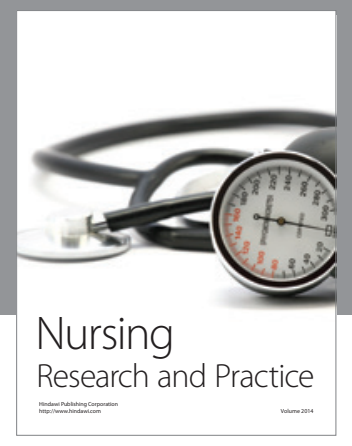

Nursing

Research and Practice

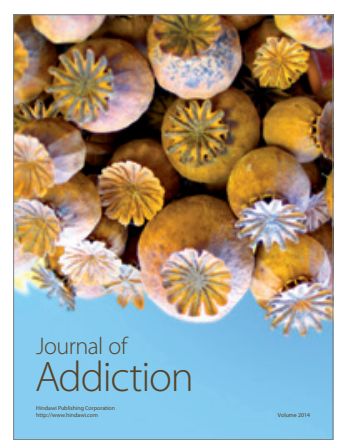

Child Development

Research

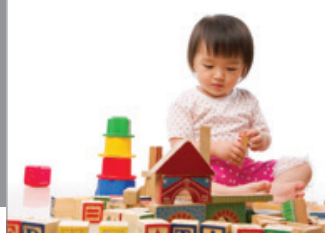

迥
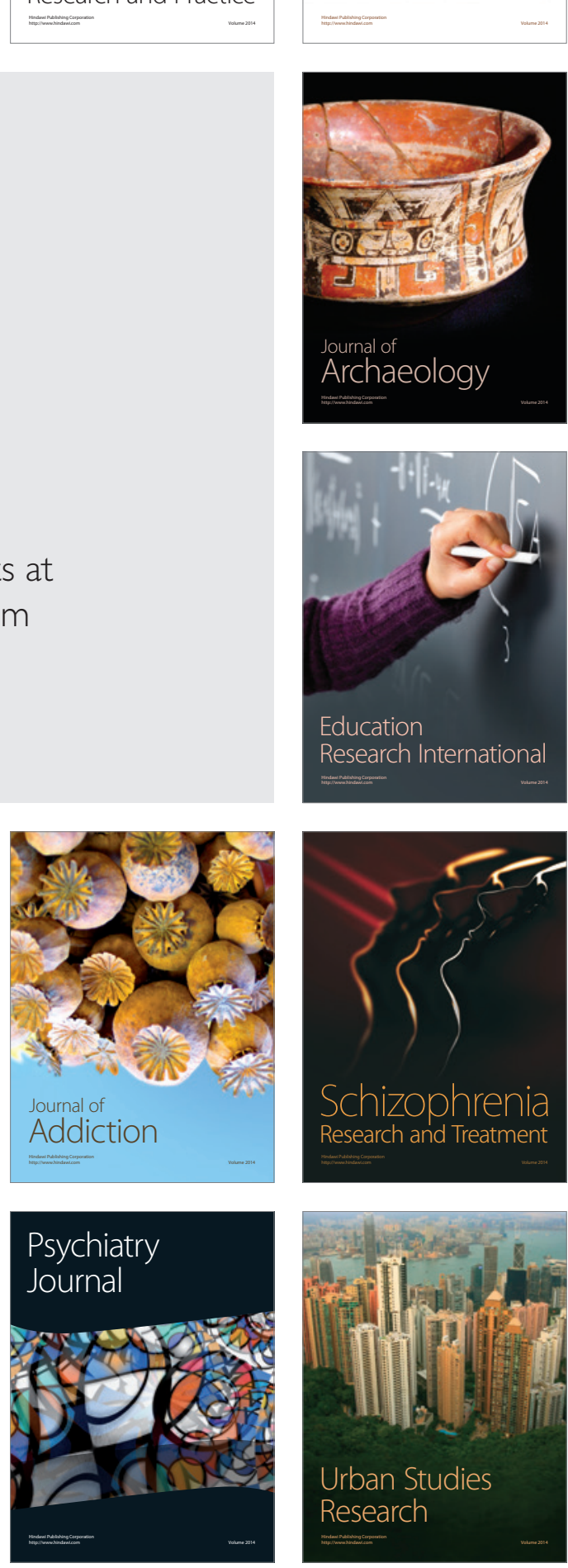